\title{
Phenotypic fitness effects of B chromosomes in the pseudogamous parthenogenetic planarian Polycelis nigra
}

\author{
LEO W. BEUKEBOOM*, MIRIAM SEIF, AMY B. PLOWMAN†, FILIP DE RIDDER \& \\ NICOLAAS K. MICHIELS \\ Arbeitsgruppe Michiels, Max-Planck-Institut für Verhaltensphysiologie, D-82319 Seewiesen, Germany
}

\begin{abstract}
B chromosomes are elements extra to the standard (A) chromosomes. Their frequencies in populations are determined by their transmission rates and effects on host fitness. Most B chromosomes are considered to be genomic parasites having transmission drive and being detrimental to their carriers. In some populations of the hermaphroditic planarian Polycelis nigra a small metacentric B chromosome is very abundant. These populations are pseudogamous parthenogenetic, meaning that sperm is needed to activate egg development, but sperm chromosomes are eliminated from the egg after fertilization. Previous transmission studies have shown that paternally inherited B chromosomes occasionally escape expulsion from the egg. Here, we compared a number of phenotypic fitness aspects of worms, with and without B chromosomes, taken from the field. B chromosomes did not significantly affect adult body size, cocoon fertility, cocoon size, hatching time and number of young per cocoon. In one of three samples cocoon production decreased significantly with increasing B number. In one of two populations, young from mothers with B chromosomes grew significantly slower than those of mothers without Bs. The dynamics of this B chromosome appear to conform to the parasitic model: Bs accumulate through occasional paternal inheritance despite being selected against through negative effects on cocoon production and juvenile growth.
\end{abstract}

Keywords: B chromosome, fitness, flatworm, Polycelis, pseudogamous parthenogenesis, selfish DNA.

\section{Introduction}

B chromosomes are chromosomes extra to the normal complement (A chromosomes) which have been found in many organisms and vary in number between individuals of a species (Jones \& Rees, 1982). In most cases, they appear to have negative effects on the phenotypic fitness of their host when they occur in high numbers. However, there have long been two opposing views as to what their effects on individual carriers are when they occur in low numbers. Under the heterotic model (White, 1973), B chromosomes are considered to have positive fitness effects at low numbers. The parasitic

\footnotetext{
*Correspondence and present address: Institute of Evolutionary and Ecological Sciences, University of Leiden, P. O. Box 9516, NL-2300 RA Leiden, The Netherlands. E-mail: beukeboom@ rulsfb.leidenuniv.nl

$\dagger$ Present address: Paignton Zoological \& Botanical Gardens, Totnes Road, Paignton, Devon TQ4 7EU, U.K.
}

model assumes that all $\mathrm{B}$ chromosomes are genomic parasites (Östergren, 1945; Nur, 1977; Werren et al., 1988; Bell \& Burt, 1990; Shaw \& Hewitt, 1990) that have negative effects on host fitness irrespective of their numbers. Both models are now considered valid (Beukeboom, 1994a; Camacho et al., 1997a): some B chromosomes can be clearly beneficial (e.g. Plowman \& Bougourd, 1994), whereas others are extremely detrimental (e.g. Werren, 1991). Recently, Camacho et al. (1997a,b) proposed a third model, the 'near-neutral' model, and presented evidence for lack of drive and obvious fitness effects of a B chromosome in the grasshopper Eyprepocnemis plorans. Although most B chromosomes appear to fit the parasitic model (Shaw \& Hewitt, 1990; Camacho et al., 1997a), too few detailed studies on transmission rates and fitness effects have been performed to warrant this conclusion fully. More studies are necessary to further our understanding of the population dynamics of supernumerary chromosomes. 
We have already described a new B chromosome system in the freshwater flatworm Polycelis nigra (Turbellaria: Tricladida) (Beukeboom et al., 1996a, 1998). Polycelis nigra is a free-living simultaneous hermaphrodite that occurs in two reproductive modes, sexual diploids and pseudogamous parthenogenetic polyploids. In pseudogamous parthenogens sperm is only used to activate egg development; paternal chromosomes are subsequently expelled and offspring are essentially maternal clones (Benazzi Lentati, 1970; Benazzi \& Benazzi Lentati, 1976). A small metacentric B chromosome was very abundant in some pseudogamous parthenogenetic populations; up to $90 \%$ of individuals carried it and numbers varied from one to three per individual (Beukeboom et al., 1996a, 1998). Surprisingly, the B chromosomes appeared to be inherited not only through the maternal line as expected, but also paternally by occasionally escaping expulsion from the fertilized egg. This can be considered as a parasitic mode of transmission and could explain their high frequencies in clonal populations. To examine further the population dynamics of this B chromosome, we collected flatworms from the field and measured effects of B chromosomes on the phenotypic fitness of their carriers.

\section{Materials and methods}

\section{Collection}

Lago di Toblino in northern Italy is a mountain lake containing a pseudogamous parthenogenetic population in which B chromosomes are abundant (see Beukeboom et al., 1996a). Worms were collected from one site along the northern shore in January (Toblino-N1) and again at the same site, as well as another site along the western shore, in July 1994 (Toblino-N2 and Toblino-W). Using a squirt bottle, animals were flushed gently from the undersides of stones picked along the shoreline. They were transported to the laboratory in $1 \mathrm{~L}$ brown plastic pots and gradually adjusted to water from a $600 \mathrm{~L}$ aquarium in the culture room.

\section{Culture}

Worms were kept individually in $200 \mathrm{~mL}$ brown plastic pots with mesh-sealed openings on two opposite sides to allow water exchange. Pots were placed in water-filled white containers at $18-22^{\circ} \mathrm{C}$ at a constant day/night cycle of $16 \mathrm{~L}: 8 \mathrm{D}$. Animals were fed twice per week ad lib. with red mosquito larvae or ground beef liver. All remaining food was care- fully removed and the water replaced within $24 \mathrm{~h}$ after feeding.

\section{Size measurements}

Immediately after collection, body size of animals was measured by taking a digital image (SMCAM II, Fast Electronic $\mathrm{GmbH}$ ) coupled to a video camera mounted on a binocular microscope (Olympus). Images were taken while animals were gliding normally in small $(6 \mathrm{~cm}$ diameter) Petri dishes halffilled with water. For the first sample (Toblino-N1), millimeter paper was placed under the worms and the images printed on a video printer. Sizes were then determined as total body length $(\mathrm{mm})$. For the two later samples an automated image analysing system (Mocha, Jandel Scientific) was available and sizes could be determined as surface area $\left(\mathrm{mm}^{2}\right)$. Cocoons and young were measured in the same way. Because cocoons are ovoid the longest axis was used in the Toblino-N1 sample. For the two later samples cocoon size was expressed as volume $\left(\mathrm{mm}^{3}\right)$ using the feret diameter (diameter of a circle with similar surface) and the formula (4/3) $\pi r^{3}$.

\section{Cocoon production}

During 4 months following collection, animals were kept singly and checked daily for the production of cocoons. Cocoons were carefully removed from the culture containers and transferred into plastic Petri dishes (diameter $6 \mathrm{~cm}$ ) half-filled with water. Cocoons were checked for emergence daily and the hatching date and number of hatchlings scored. Newly hatched young were transferred into ice-cube containers and cultured as described for adults above.

\section{Growth rate of young}

Growth rates were determined from 150 young of the Toblino-N2 and $\mathrm{W}$ samples. Young were measured at emergence and four subsequent times at fixed weekly intervals. Karyotypes of young and parents were determined afterwards according to an adjusted protocol of Redi et al. (1982) (see Beukeboom et al., 1996b).

\section{Calculation of fitness parameters}

In general, fitness parameters were first estimated per cocoon, then per animal and finally per group (e.g. with or without Bs). For example, in the case of growth rates of young, measurements were first 
averaged for all young within a cocoon, subsequently for all cocoons from an individual and finally for all individuals within a group. Nonparametric tests (MWU = Mann-Whitney $\mathrm{U}$ and KW $=$ KruskalWallis) were used to compare between groups using spss for Windows and StatXact turbo. Fitness parameters which are expressed as proportions were compared between groups using Fisher's Exact Probability test (two groups) or a $\chi^{2}$-test (three groups). If the number of individuals within a $\mathrm{B}$ chromosome class was too small, these were added to the previous class containing individuals with one $B$ fewer, e.g. if there were few animals with $2 B$ s they were added to the $1 \mathrm{~B}$ class.

\section{Statistical analysis of growth rates}

The effect of the presence of B chromosomes on the growth of young was analysed using mixed analysis of variance models containing the fixed factors population $(\mathrm{N} 2, \mathrm{~W}), \mathrm{B}$ chromosome class $(0,1,2)$ and their interaction, and random factors cocoon nested in mother and mother nested in population. These latter factors account for the possible nonindependence of measurements of young of the same cocoon and the same mother. Similar models were also fitted for each population separately. The random effects were tested using appropriate likelihood ratio tests. Fixed effects were tested using appropriate $F$-tests. Because of the unbalanced structure of the data Sattherwaite's approximation was used for the degrees of freedom. Traditional diagnostic tools (residual plots, normal probability plots) were used to check for normality and variance heterogeneity. The analyses were carried out using sAs (Littell et al., 1996).

\section{Type II errors}

In all cases, no difference between the experimental groups (B classes) was used as the null hypothesis. For nonsignificant results the Type II error, not rejecting the null hypothesis of no difference when it is false, has to be considered. Although the concept of power is often used to address this question, this approach is in fact inappropriate (Goodman \& Berlin, 1994). Instead, one has to consider a confidence interval on the estimation of the effect of interest. For our data, the effect of interest is a difference in several fitness parameters between groups of animals with different numbers of $\mathrm{B}$ chromosomes. With the nonparametric tests used, the difference between two groups is best expressed as the median shift (Lehmann, 1975). In the case of a nonsignificant difference between two groups, the confidence interval will by definition always contain zero, but the confidence limits give the maximal difference in location of the median between the two groups that cannot be excluded. In other words, one concludes that the difference between the groups is not larger than the larger of the two confidence limits. This value is the maximum not-detected difference (Max. NDD). Per test ( = per parameter), we used a confidence level of at least $95 \%$. Because of the discrete nature of some parameters and the presence of ties an exact $95 \%$ confidence interval did not always exist. In this case, a more conservative interval (usually between 95 and $99 \%$ ) was used. When three groups were compared (0B, $1 \mathrm{~B}$ and 2 or more Bs) only two a posteriori comparisons were considered $(1 \mathrm{~B}$ vs. $0 \mathrm{~B}$ and $\geq 2 \mathrm{~B}$ vs. 0B). To achieve an overall confidence level of at least $95 \%$, a level of at least $97.5 \%$ was used in each comparison. The maximum not-detected differences were reported as a percentage of the median value of the parameter in the 0B-group and usually also as a real value. For proportions a similar approach was used. Appropriate exact confidence intervals on the difference in proportion were calculated using StatXact.

\section{Results}

Table 1 compares a number of fitness parameters of animals with and without B chromosomes for all three samples. These include a total of 120 animals without B, 142 with one B, 49 with two B and two with three B chromosomes. Sample sizes differ within samples because not all parameters were measured for each individual.

\section{Adult body size}

Average body size was $\approx 7.2 \mathrm{~mm}$ (range 5.7-8.9) in Toblino-N1 and $2.9 \mathrm{~mm}^{2}$ (range 0.7-3.9) in Toblino$\mathrm{N} 2$ and $\mathrm{W}$. It did not differ between $\mathrm{B}$ classes in any sample (Table 1). These tests had maximum not-detected difference values of $6-17 \%$ with $95 \%$ confidence.

\section{Number and fertility of cocoons}

Not all individuals produced cocoons. The proportion of individuals producing at least one cocoon was $\approx 40 \%$ in Toblino-N1 and $90 \%$ in Toblino-W, and did not differ between B chromosome groups within localities (Table 1). In Toblino-N2 significantly fewer animals with B chromosomes produced 
Table 1 Adult body size, cocoon production and cocoon fertility of Polycelis nigra with and without B chromosomes from three samples

\begin{tabular}{|c|c|c|c|c|}
\hline No. of Bs & $\begin{array}{l}\text { Character studied } \\
\text { and results }\end{array}$ & $N$ & $\begin{array}{l}\text { Statistical test } \\
\text { and results }\end{array}$ & $\begin{array}{l}\text { Max. NDD } \\
\text { suffices }\end{array}$ \\
\hline \multicolumn{5}{|l|}{ Toblino-N1 } \\
\hline & Adult body size & & MWU & \\
\hline oB & $7.25 \pm 0.72$ & 37 & & \\
\hline$\geq 1 \mathrm{~B}$ & $7.21 \pm 0.72$ & 32 & $z=-0.024, P=0.981$ & $7 \%$ \\
\hline & $\begin{array}{l}\text { Proportion producing cocoons } \\
0.35 \\
0.41\end{array}$ & $\begin{array}{l}37 \\
32\end{array}$ & Fisher's Exact & 0.33 \\
\hline$\geq 1 \mathrm{~B}$ & $\begin{array}{l}0.41 \\
\text { Number of cocoons }\end{array}$ & & MWU & 0.33 \\
\hline oB & $1.62 \pm 0.77$ & 13 & & \\
\hline$\geq 1 \mathrm{~B}$ & $1.54 \pm 1.45$ & 13 & $z=-1.322, P=0.186$ & $100 \%$ ( 1 cocoon $)$ \\
\hline $\begin{array}{l}0 \mathrm{~B} \\
\geq 1 \mathrm{~B}\end{array}$ & $\begin{array}{l}\text { Proportion fertile cocoons } \\
0.54 \\
0.77\end{array}$ & $\begin{array}{l}13 \\
13\end{array}$ & Fisher's Exact & 0.60 \\
\hline $\begin{array}{l}0 \mathrm{~B} \\
\geq 1 \mathrm{~B}\end{array}$ & $\begin{array}{l}\text { Number fertile cocoons } \\
0.69 \pm 0.75 \\
0.92 \pm 0.64\end{array}$ & $\begin{array}{l}13 \\
13\end{array}$ & $z=-0.928, P=0.353$ & $100 \%$ ( 1 cocoon $)$ \\
\hline \multicolumn{5}{|l|}{ Toblino-N2 } \\
\hline $0 \mathrm{~B}$ & $\begin{array}{l}\text { Adult body size } \\
2.86+0.42\end{array}$ & 62 & KW & \\
\hline 1B & $2.88+0.35$ & 30 & & $6 \%$ \\
\hline$\geq 2 \mathrm{~B}$ & $2.81 \pm 0.48$ & 8 & $\chi_{2}^{2}=0.005, P=0.998$ & $13 \%$ \\
\hline $\begin{array}{l}0 \mathrm{~B} \\
1 \mathrm{~B} \\
\geq 2 \mathrm{~B}\end{array}$ & $\begin{array}{l}\text { Proportion producing cocoons } \\
0.72 \\
0.33 \\
0.13\end{array}$ & $\begin{array}{r}67 \\
33 \\
8\end{array}$ & $\chi_{2}^{2}=19.63, P=0.0001$ & \\
\hline$\geq 2 \mathrm{~B}$ & Number of cocoons & & MWU & \\
\hline oB & $3.88 \pm 3.11$ & 48 & & \\
\hline$\geq 1 \mathrm{~B}$ & $3.83 \pm 2.95$ & 12 & $z=-0.564, P=0.955$ & $67 \%$ ( 2 cocoons $)$ \\
\hline $\begin{array}{l}0 \mathrm{~B} \\
\geq 1 \mathrm{~B}\end{array}$ & $\begin{array}{l}\text { Proportion fertile cocoons } \\
0.69 \\
0.58\end{array}$ & $\begin{array}{l}48 \\
12\end{array}$ & $\begin{array}{l}\text { Chi-squared } \\
\chi_{1}^{2}=0.47, P=0.494\end{array}$ & 0.42 \\
\hline $\begin{array}{l}0 \mathrm{~B} \\
\geq 1 \mathrm{~B}\end{array}$ & $\begin{array}{l}\text { Number fertile cocoons } \\
2.17 \pm 2.72 \\
2.00 \pm 2.92\end{array}$ & $\begin{array}{l}48 \\
12\end{array}$ & $\begin{array}{l}\text { MWU } \\
z=-0.447, P=0.655\end{array}$ & $100 \%$ ( 1 cocoon $)$ \\
\hline \multicolumn{5}{|l|}{ Toblino-W } \\
\hline 1 & $\begin{array}{l}\text { Adult body size } \\
2.95+0.39\end{array}$ & 10 & KW & \\
\hline $1 \mathrm{~B}$ & $2.69 \pm 0.43$ & 55 & & $17 \%$ \\
\hline$\geq 2 \mathrm{~B}$ & $2.76 \pm 0.35$ & 32 & $\chi_{2}^{2}=2.452, P=0.294$ & $15 \%$ \\
\hline $\begin{array}{l}0 \mathrm{~B} \\
1 \mathrm{~B} \\
\geq 2 \mathrm{~B}\end{array}$ & $\begin{array}{l}\text { Proportion producing cocoons } \\
0.94 \\
0.86 \\
0.82\end{array}$ & $\begin{array}{l}16 \\
81 \\
38\end{array}$ & $\chi_{2}^{2}=1.42, P=0.492$ & $\begin{array}{l}0.30 \\
0.40\end{array}$ \\
\hline$\geq 2 \mathrm{~B}$ & $\begin{array}{l}\text { Number of cocoons } \\
4.93+281\end{array}$ & 15 & KW & \\
\hline $1 \mathrm{~B}$ & $4.20 \pm 2.61$ & 70 & & $50 \%$ (2 cocoons $)$ \\
\hline$\geq 2 \mathrm{~B}$ & $4.97 \pm 2.80$ & 31 & $\chi_{2}^{2}=2.346, P=0.309$ & $50 \%$ ( 2 cocoons $)$ \\
\hline
\end{tabular}

(C) The Genetical Society of Great Britain, Heredity, 80, 594-603. 
Table 1 Continued

\begin{tabular}{|c|c|c|c|c|}
\hline No. of Bs & $\begin{array}{l}\text { Character studied } \\
\text { and results }\end{array}$ & $N$ & $\begin{array}{l}\text { Statistical test } \\
\text { and results }\end{array}$ & $\begin{array}{l}\text { Max. NDD } \\
\text { suffices }\end{array}$ \\
\hline & Proportion fertile cocoons & & Chi-squared & \\
\hline OB & 0.67 & 15 & & \\
\hline $1 \mathrm{~B}$ & 0.77 & 70 & & 0.39 \\
\hline$\geq 2 \mathrm{~B}$ & 0.77 & 31 & $\chi_{2}^{2}=0.80, P=0.672$ & 0.42 \\
\hline $1 \mathrm{~B}$ & $3.23 \pm 2.69$ & 70 & & $100 \%$ ( 2 cocoons $)$ \\
\hline$\geq 2 \mathrm{~B}$ & $3.52 \pm 2.57$ & 31 & $\chi_{2}^{2}=0.595, P=0.743$ & $100 \%$ ( 2 cocoons $)$ \\
\hline
\end{tabular}

$N$, number of individuals; MWU, Mann-Whitney $U$-test; KW, Kruskal-Wallis test; Max. NDD, maximal not-detected difference (see Materials and methods). B classes were combined if the number of individuals in the upper class was too low for statistical analysis.

cocoons $(13 \%$ for $2 \mathrm{~B}$ and $33 \%$ for $1 \mathrm{~B}$ vs. $72 \%$ for $0 \mathrm{~B})$. Average numbers of cocoons ranged from 1.6 in Toblino-N1 to 4.5 in Toblino-W (range 1-12). Differences between localities result from differences in the experimental period during which cocoons were collected and from seasonal effects. No significant differences were found between B classes within localities. The maximum not-detected differences in these experiments were 1-2 cocoons. Some cocoons did not yield any young and were scored as sterile. The proportion of fertile cocoons was very similar among all B groups in all three samples and ranged from $54-77 \%$ (Table 1). Also, the total number of fertile cocoons did not differ significantly between B classes in any sample (Table 1). Again, maximum not-detected differences in these comparisons were 1-2 cocoons. In conclusion, B chromosomes did not affect cocoon production, number and fertility, except for one sample where they significantly reduced the proportion of individuals producing cocoons.

\section{Cocoon size, hatching time and number of hatchlings}

Cocoon sizes were on average $1.2 \mathrm{~mm}$ (longest axis, range $0.9-1.7$ ) in Toblino-N1 and $0.95 \mathrm{~mm}^{3}$ (volume, range 0.7-1.1) in Toblino-N2 and $\mathrm{W}$. They were similar for animals with and without $\mathrm{B}$ chromosomes in all three samples (Table 2). Maximum not-detected differences were 6-15\%. Cocoons hatched after an average of 17.8 days (range 13-27) and hatching times were similar for all $\mathrm{B}$ classes in all samples (Table 2). Maximum not-detected differences were $17-27 \%$ which correspond to 3-5 days. Fertile cocoons yielded on average 2.2 young (range
1-5) and no differences in number of young were found between animals with and without B chromosomes in any sample (Table 2). The maximum difference that could not be detected in these tests was $1-1.5$ young.

\section{Size and growth of young}

A total of 150 young from 77 cocoons and 37 mothers from Toblino-N2 and $\mathrm{W}$ was measured at emergence and at four subsequent weekly intervals. Data could be analysed in two ways depending on the developmental stage at which $\mathrm{B}$ chromosomes may exert their effect on fitness, i.e. either for presence or absence of $\mathrm{B}$ chromosomes in the mothers or in the young. Because young from the same cocoon or from different cocoons of the same mother cannot be treated independently, only the analysis for presence or absence of Bs in mothers is presented. Because most young (on average $86 \%$, $N=602$, Beukeboom et al., 1996a; 93\%, $N=132$ in this study) have the same number of B chromosomes as their mother, both analyses give similar results.

Of 37 mothers, 10 had no B, 11 had one B, eight had two B chromosomes and eight could not be karyotyped. Overall average young size was 1.10 $\mathrm{mm}^{2}$ (range 0.59-1.86) at emergence and increased to $3.29 \mathrm{~mm}^{2}$ (range 2.22-5.32), a total growth of $300 \%$ after 4 weeks. Figure 1 shows average young sizes per B chromosome class for both populations separately. At each measurement there were significant effects of cocoon and mother on size (nested ANOvAs, $P<0.05)$. This in part results from a negative correlation between the number of young that hatch from a cocoon (family size) and individual 
young size (Spearman, $r=-0.487, \quad P=0.02$, $N=37)$. Therefore, relative growth rates were used in the statistical analyses. The average number of young per cocoon per mother was not significantly different for the three B classes $\left(\mathrm{KW}, \chi^{2}=1.245\right.$, $P=0.534)$.

Relative growth rates over the entire four-week period decreased significantly with increasing B number in Toblino-W $(P=0.0005)$, but not in
Toblino-N2 $(P=0.77 ;$ nested ANovas, Table 3, Fig. 1). The interaction $B$ number $\times$ population is of special interest, because it expresses the extent to which the effect of having B chromosomes on young growth is different in the two populations. The B number $\times$ population interaction was neither significant for each weekly measurement (data not shown) nor for the relative growth rate over the entire fourweek period (Table 3 ). Because of the distribution

Table 2 Cocoon size, hatching time and number of young of Polycelis nigra with and without B chromosomes from three samples

\begin{tabular}{|c|c|c|c|c|}
\hline No. of Bs & $\begin{array}{l}\text { Character studied } \\
\text { and results }\end{array}$ & $N$ & Statistical test and results & Max. NDD \\
\hline \multicolumn{5}{|l|}{ Toblino-N1 } \\
\hline & Cocoon size & & MWU & \\
\hline 0B & $1.20 \pm 0.16$ & 13 & & \\
\hline \multirow[t]{2}{*}{$\geq 1 \mathrm{~B}$} & $1.20 \pm 0.21$ & 13 & $z=-2.056, P=0.837$ & $15 \%$ \\
\hline & $\begin{array}{l}\text { Hatch time } \\
18.0 \pm 3.1\end{array}$ & 7 & MWU & \\
\hline$\geq 1 \mathrm{~B}$ & $17.5 \pm 2.4$ & 10 & $z=-0.551, P=0.582$ & 17\% (3 days) \\
\hline $\begin{array}{l}0 \mathrm{~B} \\
\geq 1 \mathrm{~B}\end{array}$ & $\begin{array}{l}\text { Number of young } \\
1.79 \pm 1.04 \\
1.42 \pm 0.92\end{array}$ & $\begin{array}{r}7 \\
10\end{array}$ & $\begin{array}{l}\text { MWU } \\
z=-1.269, P=0.204\end{array}$ & $67 \%$ (1 young) \\
\hline \multicolumn{5}{|l|}{ Toblino-N2 } \\
\hline 0B & $\begin{array}{l}\text { Cocoon size } \\
0.97 \pm 0.10\end{array}$ & 36 & MWU & \\
\hline$\geq 1 \mathrm{~B}$ & $0.92 \pm 0.09$ & 11 & $z=-1.472, P=0.141$ & $13 \%$ \\
\hline $0 \mathrm{~B}$ & $\begin{array}{l}\text { Hatch time } \\
17.4 \pm 2.0\end{array}$ & $\begin{array}{r}25 \\
5\end{array}$ & $z=-1265 P=0206$ & \\
\hline$\geq 1 \mathrm{~B}$ & $\begin{array}{l}16.8 \pm 3.1 \\
\text { Number of young }\end{array}$ & 5 & $\begin{array}{l}z=-1.265, P=0.206 \\
\text { MWU }\end{array}$ & $18 \%$ (3 days) \\
\hline $\begin{array}{l}0 \mathrm{~B} \\
\geq 1 \mathrm{~B}\end{array}$ & $\begin{array}{l}1.99 \pm 0.77 \\
2.71 \pm 1.16\end{array}$ & $\begin{array}{r}33 \\
8\end{array}$ & $z=-1.673, P=0.094$ & $90 \%$ (1.5 young) \\
\hline \multicolumn{5}{|l|}{ Toblino-W } \\
\hline OB & $\begin{array}{l}\text { Cocoon size } \\
0.94+0.11\end{array}$ & 9 & KW & \\
\hline $1 \mathrm{~B}$ & $0.94 \pm 0.07$ & 49 & & $7 \%$ \\
\hline \multirow{2}{*}{$\geq 2 \mathrm{~B}$} & $0.95 \pm 0.06$ & 28 & $\chi_{2}^{2}=0.828, P=0.661$ & $6 \%$ \\
\hline & $\begin{array}{l}\text { Hatch time } \\
18.2 \pm 2.3\end{array}$ & 4 & $\mathrm{KW}$ & \\
\hline 1B & $17.7 \pm 2.3$ & 36 & & $22 \%$ (4 days) \\
\hline \multirow[t]{2}{*}{$\geq 2 \mathrm{~B}$} & $18.9 \pm 3.1$ & 18 & $\chi_{2}^{2}=2.322, P=0.313$ & $27 \%$ (4.8 days) \\
\hline & $\begin{array}{l}\text { Number of young } \\
2.23 \pm 0.75\end{array}$ & 10 & KW & \\
\hline 1B & $2.36 \pm 0.81$ & 54 & & $94 \%$ (1.3 young) \\
\hline$\geq 2 \mathrm{~B}$ & $2.14 \pm 0.74$ & 24 & $\chi_{2}^{2}=1.926, P=0.382$ & $85 \%$ (1.1 young) \\
\hline
\end{tabular}

$N$, number of individuals; MWU, Mann-Whitney $U$-test; KW, Kruskal-Wallis test; Max. NDD, maximal not-detected difference (see Materials and methods). B classes were combined if the number of individuals in the upper class was too low for statistical analysis.

(c) The Genetical Society of Great Britain, Heredity, 80, 594-603. 


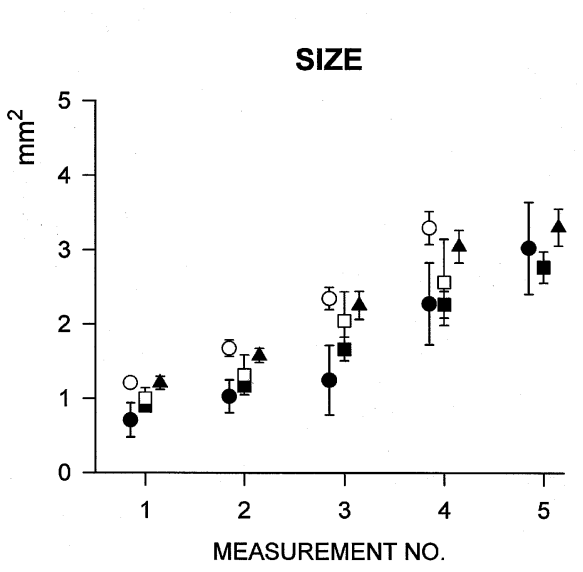

of the data over B-classes in the two populations, however, the power of the $F$-tests to detect an interaction was very limited. Because the $2 \mathrm{~B}$-class is not represented in Toblino-N2, the interaction tests only whether the difference in classes 0 and $1 \mathrm{~B}$ is the same in both populations. Moreover, there is only one $0 \mathrm{~B}$ mother in Toblino-W and only one $1 \mathrm{~B}$ mother in Toblino-N2 (Fig. 1). Therefore, a model containing the random effects and only B-class as fixed factor, was fitted for each population separately. As the absence of a significant effect of $B$ chromosomes on young growth in Toblino-N2 is based on a test with little power, the existence of substantial differences between $B$ number classes in this population cannot be excluded. The difference in overall relative growth rate between the $0 \mathrm{~B}$ and $1 \mathrm{~B}$ class is estimated as 0.26 (with $95 \%$ confidence interval: -1.78 to 2.30 ). The width of the confidence interval shows that a difference of comparable magnitude to that observed in Toblino-W cannot be ruled out.

Table 3 Effects of B chromosomes on relative growth rates of juveniles for two samples of Polycelis nigra by means of parametric ANOVA. Growth rates cover a 4-week period following eclosion

\begin{tabular}{lcrrc}
\hline Factor & $\begin{array}{c}\text { d.f. } \\
\text { effect }\end{array}$ & $\begin{array}{c}\text { d.f. } \\
\text { error }\end{array}$ & $F$ & $P$ \\
\hline $\begin{array}{l}\text { Each sample separately } \\
\text { Toblino-N2 }\end{array}$ & 1 & 5.79 & 0.1 & 0.77 \\
Toblino-W & 2 & 12.30 & 14.8 & 0.0005 \\
Both samples combined & & & & \\
$\begin{array}{l}\text { B number } \\
\text { Population }\end{array}$ & 2 & 19.9 & 4.63 & 0.0223 \\
B number $\times$ population & 1 & 18.6 & 2.25 & 0.1504 \\
\hline
\end{tabular}

\section{Discussion}

It was previously concluded that the $\mathrm{B}$ chromosome of Polycelis nigra has a selfish mode of inheritance, because it sometimes inherits through the male line in an otherwise asexual host (Beukeboom et al., 1996a). We have now shown that this B chromosome, at least when present in low numbers, does not, with one exception, exert any significant effect on fertility and fecundity of adult worms in two populations from one lake. However, it does significantly reduce the growth rate of juveniles in one, but not the other, population, even though this is not reflected in a smaller size of B-carrying adults. Because the numbers of individuals in some B-classes were small, more data are needed to substantiate a negative effect of Bs on juvenile growth. In the only other study of effects of B chromosomes in a planarian, the related Polycelis tenuis, Melander (1950) found them to delay hatching of eggs, increase susceptibility to disease and reduce 'vigour', but these conclusions are based on very few data and not statistically tested.

Maximum not-detected difference (Max. NDD) values with at least $95 \%$ confidence were used to avoid Type II errors, i.e. failing to reject the null hypothesis of no difference between B classes when it is false. For most fitness variables, these values were lower than $50 \%$ of the median, but they could occasionally reach up to $100 \%$. Although it is impossible to interpret the biological significance in terms of fitness of a difference of, for example, one cocoon, these values serve as an indication for the accuracy of our experiments.

Recently, Castro et al. (1998) pointed out that in Locusta effects of B chromosomes on carrier fitness may be a function of the frequency of $\mathrm{B}$ chromosomes in the population from which tested indi- 
viduals have been taken. Individuals from populations in which $\mathrm{B}$ chromosomes are abundant may have been selected to be more tolerant to $\mathrm{B}$ effects compared to individuals from populations in which $\mathrm{B}$ chromosomes are rare. If this were true, one would expect a stronger B effect in Toblino-N2 than in Toblino-W (average number of Bs per individual $=0.38$ and 0.90, respectively; Beukeboom et al., 1996a). The lower proportion of worms producing cocoons in the $+\mathrm{B}$ class in Toblino-N2 is consistent with this idea, but the reduced juvenile growth in the $+\mathrm{B}$ classes in Toblino-W, but not in Toblino-N2, is not. In addition, there were no significant B number $\times$ population interactions on juvenile growth. Hence, we cannot draw any firm conclusions about a population effect. Note, however, that Locusta reproduces sexually, but Polycelis asexually, and evolution of $\mathrm{B}$ tolerance could be faster in sexual organisms.

Frequencies of B chromosomes in populations are generally considered to be the outcome of loss or accumulation by meiotic and/or mitotic mechanisms on the one side and positive or negative fitness effects on the other side. Surprisingly few B chromosome systems have been studied in enough detail to quantify these selective forces precisely. Plowman \& Bougourd (1994) showed convincingly that the B chromosomes of Allium schoenoprasum are maintained in populations because of a positive effect on germination. Infinite accumulation seems to be prevented by occasional meiotic/mitotic loss and possibly detrimental effects on adult plants if the Bs are present in high numbers. The B chromosome of the wheat Aegilops speltoides (Cebriá et al., 1995) may also be considered heterotic (in the sense of White, 1973). However, most other thoroughly investigated $\mathrm{B}$ chromosomes appear to be parasitic. B chromosomes that accumulate during meiosis/ mitosis and negatively affect their host's fitness are known from the lily Lilium callosum (Kimura \& Kayano, 1961), the mealy bug Pseudococcus obscurus (Nur, 1966a,b, 1977) and the grasshoppers Melanoplus femurrubrum (Nur, 1977) and Myremeleotettix maculatus (Hewitt, 1973; Robinson \& Hewitt, 1976; Nur, 1977). Negative effects on fitness in animals include (see Jones \& Rees, 1982) reduction in larval size (Procunier, 1975), embryonic development (Nur, 1966b; Hewitt \& East, 1978), adult size (Nur, 1969a), and fertility (Nur, 1966b, 1969a,b). Although the B chromosome of Polycelis nigra shows no drastic effects on host fitness, the reduction in cocoon production and juvenile growth of B-carrying individuals observed in one population indicates that it also fits the parasitic model.
Not all B chromosomes affect the phenotypic fitness of their host. Camacho et al. (1997b) consider the B chromosome in the grasshopper Eyprepocnemis plorans to be close to selective neutrality. Transmission rates were found not to differ from 0.5 and no effects on host fitness could be detected if present in low numbers. Males of the wasp Nasonia vitripennis which carry the Paternal Sex Ratio (PSR) B chromosome (Werren, 1991) have phenotypic fitness equal to noncarrier males, but have zero genotypic fitness because their standard chromosomes are destroyed in the fertilized egg by action of the B (Beukeboom, 1994b). Bigger (1976) also did not find phenotypic fitness effects of B chromosomes in Pieris butterflies.

We previously showed that B chromosome frequencies did not significantly change in Toblino populations in the course of one generation and estimated maternal transmission rates to range from 0.74 to 0.88 and paternal transmission rates from 0.07 to 0.18 (Beukeboom et al., 1996a). The observed reduced juvenile growth is likely to have only a minor negative effect on the population frequency of the B. In addition, absence of animals with more than $3 \mathrm{Bs}$ may be the result of negative interactions among Bs when present in large numbers. Indeed, we have some preliminary data to suggest that paternal inheritance of the $\mathrm{B}$ is reduced when the egg already carries Bs of maternal origin, a phenomenon that bears similarity to negative assorted gamete fertilization for heterochromatin in two grasshoppers (López-León et al., 1996). Furthermore, other selective forces that were not identified in this study may play a role in natural populations.

Variation in chromosome number is widespread in planarians (reviewed by Benazzi \& Benazzi Lentati, 1976). Aneuploidy and supernumerary chromosomes have also been reported to occur frequently in polyploid $P$. nigra, but rarely in diploid sexuals (Lepori, 1954; Canovai \& Galleni, 1988; Canovai, 1989; Beukeboom et al., 1996a, 1997; Sharbel et al., 1998). This suggests that polyploid planarians are relatively insensitive to variation in chromosome numbers. Our study shows, however, that one or two extra small B chromosomes can have a negative effect on fitness. Recently, Sharbel et al. (1998) showed, using C-banding techniques, that proper aneuploidy may not be so common as previously believed: supernumerary chromosomes that were first considered polysomics turned out to be B chromosomes as well. Whether these B morphs also have negative effects on their host's fitness remains to be seen. In any case, the present study has shown that frequencies of supernumerary 
elements in the genome of $P$. nigra are likely to be limited by their associated negative effects on host fitness.

\section{Acknow ledgements}

A. B. P. was supported by a stipend from the Max-Planck-Gesellschaft. We thank J. P. M. Camacho for valuable suggestions to improve the manuscript.

\section{References}

BELL, G. AND BURT, A. 1990. B chromosomes: germ-line parasites which induce changes in host recombination. Parasitology, 100, S19-S26.

BENAZZI, M. AND BENAZZI LENTATI, G. 1976. Platyhelminthes. In: John, B. (ed.) Animal Cytogenetics, vol. 1, pp. 1-77. Gebrüder Borntraeger, Berlin.

BENAZZI LENTATi, G. 1970. Gametogenesis and egg fertilization in planarians. Int. Rev. Cytol., 27, 101-179.

Beukeboom, L. w. 1994a. Bewildering Bs: an impression of the 1st B-Chromosome Conference. Heredity, 73, 328-336.

Beukeboom, L. w. 1994b. Phenotypic fitness effects of the selfish B chromosome, paternal sex ratio (PSR) in the parasitic wasp Nasonia vitripennis. Evol. Ecol., 8, 1-24.

BEUKEBOOM, L. W., SEIF, M., METTENMEYER, T., PLOWMAN, A. B. AND MICHIELS, N. K. 1996a. Paternal inheritance of $\mathrm{B}$ chromosomes in a parthenogenetic hermaphrodite. Heredity, 77, 646-654.

BEUKEBOOM, L. W., WEINZIERL, R. P., REED, K. M. AND MICHIELS, N. K. 1996b. Distribution and origin of chromosomal races in the freshwater planarian Dugesia polychroa (Turbellaria: Tricladida). Hereditas, 124, $7-15$.

BEUKEBOOM, L. W., SHARBEL, T. F. AND MICHIELS, N. K. 1998. Reproductive modes, ploidy distribution and supernumerary chromosome frequencies of the flatworm Polycelis nigra (Platyhelminthes: Tricladida). Dev. Hydrobiol., in press.

BIGGER, T. R. L. 1976. Karyotypes of three species of Lepidoptera including an investigation of $\mathrm{B}$ chromosomes in Pieris. Cytologia, 41, 261-282.

CAMACHO, J. P. M., CABRERO, J., LÓPEZ-LEÓN, M. D. AND SHAw, M. W. 1997a. Evolution of a near-neutral B chromosome. Chromosomes Today, 12, 301-318.

CAMACHO, J. P. M., SHAW, M. W., LÓPEZ-LEÓN, M. D., PARDO, M. C. AND CABrero, J. 1997b. Population dynamics of a selfish B chromosome neutralized by the standard genome in the grasshopper Eyprepocnemis plorans. Am. Nat., 149, 1030-1050.

CANOVAI, R. 1989. Distribuzione dei tricladi dulcaaquicoli dei Monti Pisani con riferimento ai biotipi cariologici delle diverse specie. Atti Soc. Tosc. Sci. Nat., Mem. Ser. $B, 96,107-120$.

CANOVAI, R. AND GALlENI, L. 1988. I Tricladi dulciacqui- coli dei Monti Pisani e della pianura circostante. Boll. Mus. St. Nat. Lunigiana, 6-7, 145-149.

CASTRO, A. J., PERFECTTI, F., PARDO, C., CABRERO, J., LÓPEZ-LEÓN, M. D. AND CAMACHO, J. P. M. 1998. No harmful effects of a selfish B chromosome on several morphological and physiological traits in Locusta migratoria. Heredity, $\mathbf{8 0}$, in press.

CEBriÁ, A., NAVARro, M. L. AND PUERTAS, M. J. 1995. The effect of B chromosomes on fitness components in Aegilops speltoides Tausch. Genetica, 96, 199-205.

GOODMAN, S. N. AND BERLIN, J. A. 1994. The use of predicted confidence intervals when planning experiments and the misuse of power when interpreting results. Ann. Inter. Med., 121, 200-206.

HEWITT, G. M. 1973. Variable transmission rate of a B-chromosome in Myrmeleotettix maculatus (Thumb.) (Orthoptera: Acrididae). Chromosoma, 40, 83-106.

HEWITT, G. M. AND EAST, T. M. 1978. Effects of B chromosomes on development in grasshopper embryos. Heredity, 41, 347-356.

JONES, R. N. AND REES, H. 1982. B Chromosomes. Academic Press, London.

KIMURA, M. AND KAYANO, H. 1961. The maintenance of supernumerary chromosomes in wild populations of Lilium callosum by preferential segregation. Genetics, 46, 1699-1712.

Lehmann, E. L. 1975. Nonparametrics. Statistical Methods Based on Ranks. Holden-Day Series in Probability and Statistics. McGraw Hill, New York.

LEPORI, N. G. 1954. Nuova mutazione genomica in Polycelis nigra Ehrenberg. Caryologia, 6, 90-102.

LiTTEll, R. C., MILliken, G. A., STROUP, W. A. AND WOLFINGER, R. D. 1996. SAS System for Mixed Models. SAS Institute Inc., Cary, NC.

LÓPEZ-LEÓN, M. D., CABRERO, J. AND CAMACHO, J. P. M. 1996. Negatively assorted gamete fertilization for supernumerary heterochromatin in two grasshopper species. Heredity, 76, 651-657.

MELANDER, Y. 1950. Accessory chromosomes in animals, especially in Polycelis tenuis. Hereditas, 36, 19-38.

NUR, U. 1966a. Harmful supernumerary chromosomes in a mealy bug population. Genetics, 54, 1225-1238.

NUR, U. 1966b. The effect of supernumerary chromosomes on the development of mealy bugs. Genetics, 54, 1239-1249.

NUR, U. 1969a. Mitotic instability leading to an accumulation of $\mathrm{B}$ chromosomes in grasshoppers. Chromosoma, 27, 1-19.

NUR, U. 1969b. Harmful B chromosomes in a mealybug: additional evidence. Chromosoma, 28, 380-397.

NUR, U. 1977. Maintenance of a 'parasitic' B chromosome in the grasshopper Melanoplus femur-rubrum. Genetics, 87, 499-512.

Östergren, G. 1945. Parasitic nature of extra fragment chromosomes. Bot. Notiser, 2, 157-163.

PLOWMAN, A. B. AND BOUgOURD, S. M. 1994. Selectively advantageous effects of B chromosomes on germination behaviour in Allium schoenoprasum. Heredity, $\mathbf{7 2}$, 
$587-593$.

PROCUNIER, w. S. 1975. B chromosomes of Cnephia dacotensis and C. ornithopkilia (Diptera: Simuliidae). Can. J. Zool., 53, 1638-1647.

REDI, C. A., GARAGNA, S. AND PELlicCIARI, C. 1982. Chromosome preparation from planarian blastemas: A procedure suitable for cytogenetic and cytochemical studies. Stain Technol., 57, 190-192.

ROBINSON, P. M. AND HEWITT, G. M. 1976. Annual cycles in the incidence of B-chromosomes in the grasshopper Myrmeleotettix maculatus (Acrididae: Orthopetra). Heredity, 36, 399-412.

SHARBEL, T. F., PIJNACKER, L. P. AND BEUKEBOOM, L. W. 1998. Multiple B chromosomes in the pseudogamous parthenogenetic flatworm, Polycelis nigra: lineage markers or remnants of genetic leakage? Genome, in press.

SHAw, M. W. AND HEwITT, G. M. 1990. B chromosomes, selfish DNA and theoretical models: where next? In: Futuyma, D. \& Antonovics, J. (eds) Oxford Surveys in Evolutionary Biology, vol. 7, pp. 197-223. Oxford University Press, Oxford.

werren, J. H. 1991. The Paternal-Sex-Ratio chromosome of Nasonia. Am. Nat., 137, 392-402.

WERrEN, J. H., NUR, U. AND WU, C.-I. 1988. Selfish genetic elements. Trends Ecol. Evol., 3, 297-302.

white, M. J. D. 1973. Animal Cytology and Evolution, 3rd edn. Cambridge University Press, Cambridge. 